Filo. y Lingúi.7(1 y2):35-42,1981.

\title{
MUNDO Y CONCIENCIA EN UNA NOVELA DE ROBERTO ARLT
}

Bermal Herrera Montero *

Me propongo en las presentes líneas analizar de una manera somera la primera de las novelas del narrador argentino Roberto Arlt, El juguete rabioso (1926).

Lo anterior con dos motivos:

a) provocar en los lectores algún interés por dicho autor, en mi opinión de primera línea.

b) ir desentrañando, aunque sea de manera tentativa, el pensamiento plasmado en sus obras.

He escogido "El juguete rabioso" por dos factores, el principal de los cuales lo constituye el hecho de que es la única, de todas las obras de Arlt, en que se plantea al lector el desenvolvimiento espiritual del personaje en su viaje del mundo de la adolescencia al de los adultos, mientras que en todas las demás aparecen los personajes en la cima de su adulto desencanto. Esto tiene gran importancia ya que, de una u otra manera, este viaje nos explicará en gran parte la actitud asumida por los personajes adultos en sus demás obras.

No está de más recordar aquí que las tres primeras novelas del autor constituyen una saga novelística, aunque la crítica agrupe generalmente en una unidad tan sólo las dos novelas que continúan: "Los siete locos" y "Los lanzallamas". Esta tendencia a quedarse en obras aisladas, generalmente en aquellas tenidas como las 'cumbres' de un autor, con lo que se pierde la visión de conjunto, es muy característica de la crítica literaria latinoamericana, soliendo producir grandes errores de interpretación. Baste recordar el caso de García Márquez.

El otro motivo, intimamente relacionado con el anterior, es el hecho de que, dentro del desconocimiento general de la obra de Arlt, este suele ser aún mayor en el caso de la obra que trataremos.

Un ejemplo de lo anterior lo constituye una afirmación como la siguiente: "es Roberto Arlt (1900-1942), quien con sus novelas Los siete locos

Licenciado Bernal Herrera Montero. Profesor de Filosofía del Centro Universitario del Atlántico. Universidad de Costa Rica.
(1929) y Los lanzallamas (1931), no sólo rompe con aquella tradición novelística sino que introduce la novela típica del siglo veinte, la novela de los contextos urbanos, donde la civilización y la mecanización han hecho la vida imposible"(1). Aclarando que "aquella tradición novelística" se refiere al criollismo y al indigenismo, ¿adónde queda la primera obra arltiana? .

Antes que nada, ¿qué tipo de realidad es la que nos plantea Arlt en su obra? Una primera observación es que, a diferencia de buena parte de la literatura de su época, Arlt evita el naturalismo. Esto es, no trata de describirnos objetivamente determinados ambientes, sean estos rurales o urbanos, sino reacciones de una conciencia ante determinadas situaciones. Todos los hechos, todas las acciones que nos son contadas, no lo son por un narrador que se sitúa fuera de la acción, con una perspectiva que lo faculte para una descripción objetiva; sino por alguien directamente involucrado en la trama, el cual introduce constantemente sus estados de ánimo y reacciones sicológicas en las informaciones que nos suministra. Por esta razón, sostiene con acierto un crítico que "el discutido realismo de Roberto Arlt es un realismo psíquico, donde el mundo representado no está constituido tanto por la realidad externa cuanto por los fenómenos anímicos de sus personajes" (2).

Ejemplificando lo anterior leemos: "En los semblantes relajados por el sueño, la fatiga acrecentaba la oscuridad de las ojeras. Nuestras pupilas inmóviles permanecían fijas en los muros blancos, ora próximos, ora distantes, como en la óptica fantástica de una fiebre" (3).

Ahora bien, las relaciones del protagonista con el mundo que lo rodea no se van a mantener de manera estática, sino que se van a introducir una serie de cambios, cuya crónica será uno de los objetivos de la obra.

Dentro de esta relación dinámica que se da entre la conciencia y el mundo habrán algunos elementos que permanezcan, asumiendo diferentes matices. Uno de estos es el que constituye "un rasgo básico de la estructura subjetiva del hombre arltiano: el recurso a un mundo imaginario com- 
pensatorio"(4). Este rasgo se debe a que el personaje arltiano siempre se encuentra en tensión ante el mundo, y difícilmente logra sentirse a gusto en él. El protagonista de la obra, Silvio Astier, es un desadaptado social, un inconforme. El mundo que se le presenta ante.sus ojos, el de la gran urbe, con todo lo que esta implica, no lo satisface.

Esto lo lleva a construir un mundo privado, en el cual quebranta las leyes del conglomerado social que habita, y que le permite expresar su auténtica interioridad. En una primera etapa, puramente adolescente, este mundo es el del robo. En efecto, "gracias a los robos, Astier vive por un momento dentro de un mundo imaginario que niega las leyes del real, donde el tiempo monótono de los otros hombres es sustituido por un tiempo folletinesco formado de acontecimientos brillantes" (5).

Esta etapa es muy importante dentro de la obra ya que representa uno de los pocos momentos en que la vida es asumida con alegría por el protagonista. Este, auxiliado por la impunidad de que se siente revestido y el sentimiento de superioridad que esto le repara, ve al mundo como un gran escenario en el cual podrá realizar su más íntimo anhelo, que es el de llegar a ser un bandolero famoso y científico. En esta época nos dice: "Así conversábamos en torno de la mesa del café, sombríos y gozozos de nuestra impunidad ante la gente, ante la gente que no sabía que éramos ladrones, y un espanto delicioso nos apretaba el corazón al pensar con que ojos nos mirarían las nuevas doncellas que pasaban si supieran que nosotros, tan atilados y jóvenes, éramos ladrones" (6).

Ya a partir de aquí surge otra constante que se mantendrá a lo largo de la obra, y que es la diferencia radical entre la mirada objetivadora que echa el conjunto social sobre el personaje, y la mirada interna con que éste se ve a sí mismo.

Uno de los motivos principales que tiene el protagonista para dedicarse al robo, más importante que su pobreza, es el deseo de no ser un hombre común más. El temor a la vida gris que está reservada a los miembros de su clase le espanta, y temeroso de engrosar el nutrido ejército de los mediocres, busca llevar una vida intensa y llena de aventuras, que el mismo personaje nos describe de la siguiente manera: "Entonces yo soñaba con ser bandido y estrangular corregidores libidinosos; enderezaría entuertos, protegería a las viudas y me amarían singulares doncellas" (7).
Inclusive es esta la única época en que el personaje se siente solidario con otras personas, sus compinches, con los cuales funda un club, el de "Los Caballeros de la Medianoche", con el ánimo de ir robando y matando de manera cada vez más científica.

Sin embargo, todo este mundo interior y las realizaciones que conlleva, se ve destruido en el momento en que están a punto de ser capturados por la policía.

Derrumbada la impunidad que creía gozar el personaje, la relación entre la conciencia y el mundo va a ser totalmente cambiada. Si antes era el personaje quien imponía una imagen falsa a la sociedad, humillándola, ahora va a ser la sociedad quien le imponga su imagen, igualmente falsa, al personaje, y será este el humillado. Si anteriormente la imaginaria impunidad de que disfrutaba anulaba la mirada social echada sobre él, al perder ese mundo interior tal mirada penetrará en el personaje, el cual ha perdido su barrera protectora, y calará hasta lo más hondo de su persona.

De esta segunda etapa nos dice Silvio: "y una agria tiniebla de miseria se enseñoreó de mis días" (8).

En la situación social en que el personaje se encuentra, de muchacho pobre desocupado y destinado a bajos oficios, el protagonista se siente humillado. ¿En qué consiste esta humillación? En el total desfase entre sus aspiraciones íntimas y su reconocimiento social, entre lo que piensa que es o podría ser, y lo que socialmente es. "Su persona social niega, a sus ojos, su persona íntima; pero, incapaz de formular otro proyecto como alternativa, deberá asumir su realidad degradada, es decir, la imagen que los otros le imponen de sí mismo. La interiorización de su imagen social - para él, el despojo de sí mismo- lo hace sentirse humillado" (9).

Pasando el momento en que se creía poder construir un mundo privado, separado del cotidiano, la lucha es por el reconocimiento social de su persona íntima, de lo que él cree ser en realidad. Si antes se contentaba con mostrarse como lo que realmente no era, ahora opta por tratar de imponerse ante el mundo de una manera en que éste pueda aceptarlo. El camino que escoge, y para el cual ya había dado muestras de habilidad, es el de inventor. Observemos la profunda diferencia entre la opción del robo y la del invento. Ya que la condición para realizarse exitosamente como ladrón es la de no ser descubierto, conviene el no ser reconocido socialmente como tal. En este sentido, 
como ya vimos, la mirada social no afecta ya que interiormente hay una realización en el sentido que se desea. En cambio, de inventor cambia la cosa. Nada gana el protagonista con sentirse como tal, si no hay simultáneamente un reconocimiento social de dicha condición. Ahora sí afecta fuertemente el como sea visto. En consecuencia, mientras la sociedad no reconozca a Silvio en la manera en que este desea serlo, sentirá que está siendo anulado, negado.

La relación entre el mundo y el protagonista originada en este desacuerdo es, como ya hemos visto, de humillación. Lo interesante es que dicho sentimiento es el que salva al protagonista de sentirse totalmente anulado. Veamos esto con más detenimiento. Ya hemos visto el desfase que dicho sentimiento implica entre lo que se es personal y socialmente. En tanto el personaje se sienta humillado, es porque hay conciencia de esta situación; es porque, si bien se ha interiorizado la mirada social, no se ha olvidado la íntima, lo que realmente se cree ser. La humillación implica la certeza de que se es algo más que lo que la sociedad nos reconoce; y el momento en que este sentimiento desaparezca, será el momento en que coinciden lo que la sociedad cree del personaje con lo que cree este de sí mismo. Entonces, se habrá claudicado.

De este desfase causa de la humillación se hace consciente el protagonista, el cual exclama: “-Oh, ironía! , y yo era el que había soñado en ser un bandido grande como Rocambole y un poeta genial como Baudelaire!

Pensaba:

$-i \mathrm{Y}$ para vivir hay que sufrir tan-
to...? $(10)$.
Y posteriormente, entreviendo el lado positivo de la humillación, lo que implica esta de dignidad, piensa: "Era necesario eso, sí, eso; era necesario que mi vida, la vida que durante nueve meses había nutrido con pena un vientre de mujer, sufriera todos los ultrajes, todas las humillaciones, todas las angustias" (11).

Es por esto por lo que tiene razón un comentarista al decirnos que "la conducta de los sujetos se muestra no solamente como determinada e inducida externamente sino también como internamente aceptada por renuncia o ejercicio de la voluntad personal" (12).

Ahora bien, toda esta conducta, ia qué motivaciones responde? En última instancia, a un rechazo de los valores que la sociedad dice sustentar, y que lo que producen es la alienación del individuo. Hay en la obra una fuerte crítica de los valores establecidos, que rigen la vida de las sociedades urbanas, del tipo en que le tocó vivir al autor. Lo que sucede es que dicha crítica es un tanto indirecta.

$\mathrm{Si}$ analizamos con atención, veremos que aquellas cosas concretas que humillan al personaje, no necesariamente provocarian esa reacción en gran parte de la gente. Cuando don Gaetano, el patrón de la librería en que trabaja Silvio, lo lleva al mercado de compras con una gran canasta, y nota que se siente humillado, le dice: "-Parece que tenés vergüenza de llevar una canasta. Sin embargo, el hombre honesto no tiene vergüenza de nada, siempre que sea trabajo" (13).

Así, no son los hechos en sí los que humillan, es simplemente el no reconocimiento de sus mejores cualidades lo que hace a Silvio sentirse incómodo, en donde otros no lo estarían. Desde este punto de vista, los hechos en sí son neutros, la crítica se dirige al proceso más hondo de la alienación, que implica la imposibilidad para el ser humano de realizarse como aquello que está en capacidad de ser.

$\mathrm{Al}$ respecto se ha afirmado: "Constituye una constante de su obra la sátira del capitalismo yanqui, que en definitiva se subordina a la intención final, o sea la denuncia del proceso alienatoriu operado por el industrialismo y sus espectros: lo que define todo esto es la sátira de la alienación" (14).

Ya se había apuntado hacia esta dirección en la etapa anterior del protagonista, la de los robos. Uno de los alicientes para esto era el evitar ganarse el dinero por los medios socialmente aceptados, que se revelan como alienantes. "Sí, el dinero adquirido a fuerza de trapacería se nos fingía mucho más valioso y sutil, impresionaba en una representación de valor máximo, parecia que susurraba en las orejas un elogio sonriente y una picardía incitante. No era el dinero vil y odioso que se abomina porque hay que ganarlo con trabajos penosos" (15).

Así como la crítica no es al dinero en sí, sino a la forma de ganarlo, la denuncia de la alienación no implica el ataque a determinadas estructuras o modos de conducta social, sino a la negación de la intimidad del ser humano, como quiera que esta se produzca.

Observemos que en esta primera etapa de la humillación, esta se debe, aparentemente, a que la sociedad no ha reconocido los posibles méritos que como inventor tiene Silvio. O sea, se origina en un 
desconocimiento social de las capacidades del individuo. Este, desesperado, trata de borrar lo que cree fuente de su humillación, el lugar de trabajo, mediante un acto en que se afirme a sí mismo ante su lugar social, y trata de destruirlo. Para esto, intenta incendiar la librería en que trabaja.

Mediante dicho acto, el personaje se rescata a sí mismo como conciencia que se opone al mundo exterior, que no acepta sus determinaciones. La noche del atentado, cuando aún ignora el fracaso de este, el estado de ánimo de Silvio es el siguiente: "En la oscuridad yo sonreía libertado... libre... definitivamente libre, por la conciencia de hombría que me daba mi acto anterior. Pensaba, mejor dicho, no pensaba, anudaba delicias" (16). Notemos aquí que se da en Silvio todavía una cierta conciencia ingenua de su humillación, puesto que se imagina que haciendo desaparecer el lugar físico donde esta ocurre, desaparecerá la causa. En el análisis de la siguiente etapa, se verá la falsedad de esta ilusión.

Pero antes de esto, analicemos una consecuencia que trae este estado de humillación en el protagonista: el acorazamiento que se va creando respecto a su mundo externo, el cual tiene su manifestación física en la sordera que ataca a Silvio en esta época. Se da una incomunicación casi total entre el mundo social y la conciencia protagónica del relato. Los sentimientos de solidaridad, presentes en la etapa anterior, se desvanecen, con la consiguiente pérdida de toda posible solidaridad social. Con su compañero de desgracias, el viejo Dío Fetente, no logrará establecer una auténtica corriente de simpatía, sino tan sólo un sentimiento de conmiseración. De igual manera, este encorazamiento le impide a Silvio crear, como en la etapa de los robos, un mundo imaginario eficaz para oponer al mundo real. El recurso a la imaginación quedará siempre como una posible evasión hacia un mundo más hermoso que el impuesto por las circunstancias, pero ya no proporcionará una alternativa real y eficaz de acción. El siguiente testimonio no puede ser más claro: "Alli comencé a quedarme sordo. Durante algunos meses perdí la percepción de los sonidos. Un silencio afilado, porque el silencio puede adquirir hasta la forma de una cuchilla, cortaba las voces en mis orejas.

No pensaba. Mi entendimiento se embotó en un reconcor cóncavo, cuya concavidad hacíase día a día más amplia y acorazada. Así se iba retobando mi rencor" (17).

En la siguiente etapa, se da un reconocimien- to social de lo que el personaje cree constituye un núcleo de su intimidad: sus aptitudes para la mecánica y la invención. Recordemos que tal reconocimiento era una de las metas de Silvio. Gracias a estas habilidades es admitido como aprendiz en uno de los talleres del ejército argentino, con lo cual siente renacer la convicción del destino grandioso a cumplirse en mi existencia. Yo podría ser un ingeniero como Edison" (18). Sin embargo, tal alegría le dura poco ya que, debido a sus mismas cualidades, es expulsado de su trabajo. En efecto, quien lo despide le dice: "Aquí no necesitamos personas inteligentes, sino brutos para el trabajo" (19). Con esto, se rompe la ilusión anterior de que su humillación proviene de un no reconocimiento de sus cualidades, ya que ahora le viene precisamente de dicho reconocimiento.

Ante este rechazo social de su persona, opta el personaje por una evasión aún más radical, y decide irse a Europa, por lo que va a ofrecerse en los barcos para cualquier trabajo, pero de todos es rechazado. Con esto llegamos a uno de los puntos álgidos de la obra: el proyecto de suicidio. Ya hemos visto como constantemente Silvio se ha evadido, de muchas formas, hacia mundos que son contemplados como mejores que el fáctico, y que pueden tener más o menos coherencia y eficacia social. Esto está intimamente relacionado con la "persistente intuición del acontecer habitual como algo extraño; la conciencia que algunos personajes tienen de sí mismos como de ser extranjeros en el mundo, la sensación de desarraigo en la tierra" (20) que se agudiza conforme se va acentuando el estado de humillación. A medida que este último va ganando terreno, la evasión va siendo cada vez menos hacia un mundo coherente imaginariamente estructurado, y va adquiriendo un carácter más inconexo y menos eficaz. Este proceso que tiene su momento cumbre en el instante en que la humillación viene del reconocimiento de la interioridad del personaje borrando con esto la última esperanza, nos lleva por una lógica interna implacable, a la evasión en su forma más acentuada: el suicidio.

Porque aquí el suicidio no está planteado como la aniquilación última de la persona, en cuyo caso no constituiría una evasión, sino tan solo como una manera de llegar al mundo que tan frecuentemente se desea. No es más que la última posibilidad de anulación de las determinaciones concretas a que está sometido el personaje, y que éste repudia. Veamos cómo razona Silvio: "Ya en otras circunstancias, la teatralidad que secunda con 
lutos el catafalco de un suicida, me había seducido con su prestigio.

Envidiaba a los cadáveres en torno de cuyos féretros sollozaban las mujeres hermosas, $\mathrm{y}$ al verlas inclinadas al borde de los ataúdes se sobrecogía dolorosamente mi masculinidad.

Entonces hubiera querido observar el suntuoso lecho de los muertos, como ellos ser adornados de flores y embellecido por el suave resplandor de los cirios, recoger en mis ojos y en la frente las lágrimas que vierten enlutadas doncellas" (21).

Y la esencia misma del razonamiento, que lo que justifica es una evasión y no una aniquilación, es captada lúcidamente por él cuando a continuación afirma: “-No he de morir, no..., yo no puedo morir..., pero tengo que matarme.

(...)

Mi mente se despejó de sensaciones secundarias; yo sólo era un latido de corazón, un ojo lúcido y abierto al serenísimo interior. me" (22).

-No he de morir, pero tengo que matar-

Convencido el personaje de que lo que quiere es ingresar en otro mundo mejor no se dispara en la cabeza sino en el corazón, al igual que Erdosain en "Los lanzallamas", para estar bien presentado al teatral ambiente al que cree que llegará.

Sin embargo, su intento fracasa al fallar el revólver. Así, todas las tentativas de evasión parecen condenadas al fracaso, y el personaje condenado irremisiblemente a integrarse al ejército de los mediocres que pululan de un trabajo a otro, en medio de humillaciones. Es este el momento en que se inicia la cuarta y última parte de la novela que, en razón de haberse cerrado un ciclo vital en la búsqueda del personaje, pareciera augurar uno nuevo.

$Y$, en efecto, encontramos en esta parte a Silvio Astier empleado de agente vendedor de una papelería, y esforzándose al máximo por vender. Nos dice por ejemplo que "durante una semana caminé seis horas por día inútilmente. Aquello era inverosímil. No vendí un kilo de papel en el trayecto de cuarenta y cinco leguas. Desesperado entraba a verdulerías, a tiendas y almacenes, rondaba los mercados, hacía antesala a farmacéuticos y carniceros, pero inútilmente" (23).

Pareciera que el personaje, persuadido de que no hay escapatoria posible, está decidido a buscar un cierto reconocimiento social, a acomodarse en el engranaje colectivo. De hecho empieza a vender y al hacerlo siente que una gran "alegría, dionisíaca alegría inverosímil, ensanchaba mi espíritu hasta las celestes esferas" (24). La evasión siempre se da, pero ahora dentro de los límites normales aceptados por la sociedad. Casi que se da una idealización, aunque sea contrastante, del ambiente en que se desenvuelve en sus recorridos. A propósito de estos nos dice: "Mis ojos bebían ávidamente la serenidad infinita, extática en el espacio celeste.

Llamas ardientes de esperanza y de ensueño envolvíanme el espíritu y de mí brotaba una inspiración tan feliz de ser cándida, que no acertaba a decirla con palabras.

Y más y más me embelesaba la cúpula celeste, cuanto más viles eran los parajes donde traficaba" (25). Y Silvio, que antes renegaba del mundo en que vivía, llega a afirmar: "Complacíame el espectáculo de los grandes almacenes interiormente sombrosos, las queserías frescas como granjas con enormes pilones de manteca en los estantes, las tiendas con multicolores escaparates y señoras sentadas junto a los mostradores frente a livianos rollos de telas; y el olor a pintura en las ferreterías, y el olor a petróleo en las despensas, se confundía en mi sensorio, como el fragante aroma de una extraordinaria alegría, de una fiesta universal y profunda, cuyo futuro relator fuera yo" (26).

Silvio se ha reconciliado con el mundo.

Sin embargo, repentinamente sucede algo totalmente inesperado. En su trajinar por las calles, se ha hecho amigo del Rengo, cuidador de carros de un mercado, el cual llega a tenerle a Silvio bastante aprecio y confisiza. Un día, el Rengo se presenta a casa de Silvio y, tras andar con algunas cautelas, hace partícipe a este de un proyecto de robo que piensa cometer esa misma noche. Dicho robo, que no parece poder fracasar, producirá una considerable suma de dinero. Silvio acepta participar pero, sin aparente motivo, se dirige a donde la persona que va a ser robada $y$, traicionando a su amigo, le cuenta todo el plan. El Rengo y una cómplice son prendidos por la policía, y el delator se niega a recibir dinero por su delación. Sin embargo, le pide ayuda al ingeniero al que salva del robo para dirigirse "al Sur... al Neuquén... allá donde hay hielos y nubes... y grandes montañas..." (27). El ingeniero le promete ayuda, y con esto concluye la novela. Ahora bien, cuáles son los motivos, si es que tiene alguno, de Silvio para traicionar a su amigo?

La bibliografía consultada nos da principalmente dos respuestas. 
a) La de Angel Núñez (28), quien lo explica diciendo que el ejercicio gratuito del mal es dentro del mundo del crimen, de los humillados y los disminuidos, una forma de liberación, de recuperar la humanidad perdida.

b) La de Diana Guerrero, en su libro ya citado, quien afirma, dentro de una perspectiva principalmente sociológica, que Silvio actúa de esta manera para evitar su identificación con el lumpen. En efecto, para esta autora, cuya crítica es la mejor de las leídas, la motivación principal de los problemas y ambigüedades de Silvio consiste en que "no puede integrarse a su clase, por rechazar su mediocridad efectiva, ni a la del Rengo, porque los principios abstractos de la pequeña burguesía continúan siendo los suyos" (29). En cuanto al mundo de los ricos, que en esta interpretación es el mundo idealizado por el personaje, el mundo al que se desearía pertenecer por poseer los más altos valores y realizaciones, es claramente inaccesible.

También afirma que es el deseo de perseverar en su individualidad concreta lo que "lo conduce, frente al Rengo, a no borrar las diferencias entre ellos, garante de su carácter peculiar" (30).

Con respecto a la primera interpretación, es mi opinión personal que constituye tan sólo uno de los elementos de interpretación. En primer lugar, ya el mismo personaje ha experimentado, a través del fallido incendio, que tales actos por su ineficacia no conllevan ninguna liberación. Por otro lado, no se puede hablar de Silvio como de alguien que haya perdido su humanidad, ya que la sensación de humillación que se palpa en gran parte de la obra es el resultado de la exsacerbada conciencia que posee el personaje de tener tal característica. Y, en último lugar, en el momento en que se da el acto de traición, es cuando mayor asimilación ha tenido Silvio con respecto al mundo que lo rodea. Así, si bien esta interpretación nos da un valioso indicio explicativo, el que apunta hacia el valor de recuperación de algo perdido que tiene el acto en cuestión, no podemos decir que aclare totalmente el asunto.

Tocante a la explicación de Guerrero, nos parece que ha habido una sobrevaloración de los determinantes clasistas que, indudablemente, aparecen en la obra. Es muy discutible, y en mi opinión falso, que el personaje comparta los "principios abstractos de la pequeña burguesía", ya que en su accionar, principal elemento de juicio, no los acepta ni respeta. Además, si bien es cierto que se da una cierta idealización del mundo de los ricos en la conciencia del personaje, esta obedece a la total ignorancia que tiene Silvio de tal mundo. No está de más decir que, en las obras posteriores del autor, tal idealización desaparece completamente. Ya un autor, Pío del Corro, nos ha señalado que, si bien es cierto que Arlt a veces plantea el problema de clase, definitivamente no se queda en él.

En cambio, sí parece acertar cuando nos habla del intento del personaje por conservar y defender su propia individualidad. En efecto, se nota a través de toda la obra una gran preocupación en Silvio por hacer valer su propia personalidad, por no dejarse hundir en la colectividad, a través del ejercicio de características que sean propias y peculiares. Si recordamos la lógica interna de la obra, y las características de las primeras tres etapas, nos daremos cuenta de que en ellas no se presentaba el problema de hundirse en la colectividad. Era tal el antagonismo de Silvio con el mundo que le rodeaba, aunque este antagonismo asumiera diversas manifestaciones, que no había posibilidad de una disolución en dicho mundo, ya que constituían los polos de una relación de enfrentamiento, de oposición. En cambio, en la última etapa, ya ha habido una gran asimilación del personaje con el mundo, por lo que ya es muy factible la pérdida de la propia individualidad. Hay en esta etapa un encuentro que es muy significativo, y es el que tiene Silvio con Lucio, uno de sus excompinches en la primera época, la de los robos. Lucio le cuenta que el tercer compañero de oficio, Enrique, ha acabado en la cárcel, ya que fue de los tres el único que siguió actuando al margen de los valores sociales. Lucio por su parte ya está totalmente identificado con estos valores, al extremo de que es un agente pagado por la sociedad para velar por ellos, es policía. Por medio de este encuentro, Silvio se habrá dado cuenta de su situación de asimilación, así como de lo lejos que han quedado sus sueños de adolescente; y encuentra una salida para retomar su vieja personalidad, que ya se encontraba al borde al colapso, en la delación que hace de los planes del Rengo.

Tal delación hará posible nuevamente un cierto estado de interiorización en busca de una explicación a sí mismo, ya que el problema de su personalidad nuevamente se pondrá en primer plano. Al pensar en delatar a su amigo, se pregunta: " - ¿Por qué no? ... Entonces yo guardaré un secreto, un secreto salado, un secreto repugnante, que me impulsará a investigar cuál es el origen de mis raíces oscuras. Y cuando no tenga 
nada que hacer, y esté triste pensando en el Rengo, me preguntaré: ¿Por qué fui tan canalla?, y no sabré responderme, y en esta rebusca sentiré como se abren en mí curiosos horizontes espirituales"(31). Siente renacer sus viejas ambiciones, como el parecerse a Rocambole, de quien dice que también traicionó constantemente sin importarle. De igual manera, resurge el deseo de huir del lugar físico que se habita. Aquí hay que preguntarse porqué, si lo que deseaba era volver a su etapa anterior, no se involucró en el robo. Mi respuesta es que ya el personaje ha experimentado en carne propia las consecuencias que esto podría traerle y no está dispuesto a enfrentarlas. Además, ya ha desaparecido de él todo sentimiento de solidaridad, y no parece dispuesto a comprometerse con nadie, especialmente si esto le podría acarrear algún problema en el futuro.

De este modo, creo que la explicación a la traición se encuentra en el deseo de perpetuar su individualidad que siente Silvio, y esto responde a la lógica interna que ha venido desarrollando la obra. En efecto, el paso de una a otra de las cuatro etapas en la vida del personaje se debe a una dialéctica propia de la obra, mediante la cual el personaje se va explorando a sí mismo, a sus potenciales, $y$ al mundo en que le ha tocado vivir. Llegado el momento en que, al convertirse en adulto, se enfrenta al dilema entre la asimilación y la diferenciación con su ambiente, escoge esta última alternativa.

Ahora bien, una vez escogida ésta, ¿cuál será el accionar del protagonista arltiano, ya adulto y formado, en un mundo del cual ha aprendido que no puede evadirse? La respueta a esta pregunta solo podrá dársela el lector conforme se vaya introduciendo en el examen del resto de la obra de ese precursor que se llamó Roberto Arlt.

\section{NOTAS}

( 1) Gostautas Stasys, La evasión de la ciudad en las novelas de Roberto Arlt, en Revista Iberoamericana, v. 38, n. 80,1972 p. 441

( 2) Pío del Corro Gaspar, La zona novelística de Roberto Arlt, Universidad Nacional de Córdoba, Buenos Aires, 1977, p. 14

( 3) Arlt Roberto, El juguete rabioso, Ed. Losada S. A., Buenos Aires, $3^{\text {ra. }}$ edición, 1975 , p. 36

(4) Guerrero Diana, Roberto Arlt, Granica Editor, Buenos Aires, 1972, p. 19

( 5) ibid., p. 23

(6) Arlt Roberto, op. cit., p. 23

( 7) ibid., p. 9

( 8 ) ibid., p. 41

( 9) Guerrero Diana, op. cit., p. 14

(10) Arlt Roberto, op. cit., p. 48

(11) ibid., p. 66

(12) Pío del Corro Gaspar, op. cit., p. 12

(13) Arlt Roberto, op. cit., p. 48

(14) Pío del Corro Gaspar, op. cit., p. 10
(15) Arlt Roberto, op. cit., p. 22

(16) ibid., p. 68

(17) ibid., p. 66

(18) ibid., p. 78

(19) ibid., p. 85

(20) Pío del Corro Gaspar, op. cit., p. 24

(21) Arlt Roberto, op. cit., p. 97

(22) ibid

(23) ibid., p. 100

(24) ibid., p. 101

(25) ibid., p. 106

(26) ibid., p. 107

(27) ibid., p. 135

(28) Núñez Angel, La obra narrativa de Roberto Arlt, Ed. Nova, Buenos Aires, 1978

(29) Guerrero Diana, op. cit., p. 41

(30) ibid., p. 43

(31) Arlt Roberto, op. cit., p. 31 


\section{BIBLIOGRAFIA}

Arlt Roberto, El juguete rabioso, Ed. Losada S. A., Buenos Aires, 1975

Gostautas Stasys, La evasión de la ciudad en las novelas de Roberto Arlt, en Revista Iberoamericana, v. 38 , n. 80,1972

Guerrero Diana. Roberto Arlt, Granica Editor, Buenos Aires, 1972

Núñez Angel, La obra narrativa de Roberto Arlt, Ed. Nova, Buenos Aires, 1978
Pío del Corro Gaspar, La zona novelística de Roberto Arlt, Universidad Nacional de Córdoba, Buenos Aires, 1977

Scari Robert, La novela moderna en Roberto Arlt, en Cuadernos Hispanoamericanos, n. 255, marzo, 1971

Scari Robert, Roberto Arlt, escritor maduro $y$ adolescente, en Cuadernos Americanos, v. 187 , n. 2 , marzo-abril, 1973 